5. Verhoeff FH. Histological findings in a case of angioid streaks. Br J Ophthalmol 1948;32:531.

6. Gass JDM, Clarkson JG. Angioid streaks and disciform macular detachment in Paget's disease (osteitis deformans). Am J Ophthalmol 1973;75:576-86.

7. Jensen OA. Bruch's membrane in pseudoxanthoma elasticum: histochemical, ultrastructural and x-ray microanalytical study of the membrane and angioid streaks areas. Graefes Arch Klin Exp Ophthalmol 1977;203:311-20.

8. Dreyer R, Green WR. The pathology of angioid streaks: a study of twenty-one cases. Trans Pa Acad Ophthalmol Otolaryngol 1978;31:158-67.

9. Jampol LM, Acheson R, Eagle RC, et al. Calcification of Bruch's membrane in angioid streaks with homozygous sickle cell disease. Arch Ophthalmol 1987;105:93-8.

10. Torczynski E. Choroid and suprachoroid. In: Jakobiec FA, editor. Ocular anatomy, embryology, and teratology. Philadelphia: Harper and Row, 1982:572.

11. Bird AC. Bruch's membrane change with age. Br J Ophthalmol 1992;76:166-8.

12. Newsome DA. Retinal dystrophies and degenerations. New York: Raven Press, 1988:271.

13. Hogan MJ, Alvarado J. Studies on the human macula. IV. Aging changes in Bruch's membrane. Arch Ophthalmol 1967;77:410-20.

14. Feeney-Bums L, Ellersieck MR. Age-related changes in the ultrastructure of Bruch's membrane. Am J Ophthalmol 1985;100:686-97.

15. Sarks SH. Ageing and degeneration in the macular region: a clinico-pathologic study. Br J Ophthalmol 1976;60:324-41.

Ahmad M. Mansour, MD

Department of Ophthalmology

American University of Beirut

Beirut

Lebanon

A.M. Mansour

Montefiore Medical Center

Albert Einstein College of Medicine

Bronx

New York, USA

Paul Henkind (deceased)

Sir,

\section{Post-operative myopic shift due to trapped intracapsular Healon}

We describe a rare post-operative complication caused by Healon trapped within the capsular bag behind a posterior chamber intraocular lens. This resulted in a shallowed anterior chamber and a myopic shift, both of which were corrected by removal of the trapped Healon.

\section{Case report}

A 76-year-old woman complaining of blurred vision in her left eye was diagnosed as having a cortical cataract. Her visual acuities were 6/12 right and 6/18 left. Anterior and posterior segment examination was otherwise unremarkable and in particular she had normal anterior chamber depths (right $2.47 \mathrm{~mm}$, left 2.55 $\mathrm{mm}$ ). The patient agreed to a left cataract extraction with intraocular lens implantation. Her pre-operative refraction was $+3.75 /-2.50$ in her right eye and $+1.50 /-1.75$ in her left eye. The aim was to make the left eye emmetropic and the posterior chamber lens needed to achieve this was a 23 dioptre lens. An uneventful left phacoemulsification using a foldable intraocular implant (8590B Chiron) inserted under sodium hyaluronate 5000 (Healon) was carried out after a continuous circular capsulorhexis. The Healon was aspirated from in front of the implant at the end of the operation.

Post-operatively she had a visual acuity of $6 / 6$ and a refraction of $-1.75 /-1.75$. A shallow anterior chamber was noted. A greater than normal distance between the posterior surface of the intraocular lens and the surface of the posterior capsule was also noted. The shallow anterior chamber, distended capsular bag and refraction remained unchanged over the following 2 months. It was decided that the Healon needed removing from the capsular bag and that this should be done surgically as the capsulorhexis edge was obscured by the pupil margin (even when the pupil was dilated). The Healon was aspirated after inserting a cannula into the capsular bag between the edge of the intraocular lens optic and the capsulorhexis margin. The procedure was uneventful.

Post-operatively the patient's vision remained at 6/6, but the anterior chamber deepened, the capsular bag distension disappeared and her refraction improved to $-0.25 /-0.50$. At no stage was there excessive intraocular inflammation or raised intraocular pressure and the Healon remained clear throughout this 2 month period.

\section{Comment}

Hyaluronic acid is a naturally occurring glycosaminoglycan which, due to its viscosity, elasticity and other properties, acts as an ocular lubricant and an anterior chamber depth maintainer. Formulations of exogenous hyaluronic acid for clinical use are derived from the dermis of rooster combs or by fermentation in streptococcal cultures. The physical properties of hyaluronic acid and its use in ophthalmic surgery have been described in several detailed reviews. ${ }^{1-4}$ The high viscosity when stationary permits maintenance of depth and shape of the anterior chamber and manipulation of tissues, and the low viscosity when forced through a cannula facilitates removal and injection. It reduces the damage to the corneal endothelium during intraocular surgical manipulation.

It has been shown in animal experiments that the halflife of exogenous hyaluronic acid in the anterior chamber of the eye is directly related to the injected volume. ${ }^{5}$ It is uncertain how this is related to molecular weight. ${ }^{6,7}$ Local catabolisation of hyaluronic acid after its injection into the anterior chamber is negligible. Data in rabbits indicate that it is degraded mainly in the liver after diffusion from the eye into the plasma. In our case the Healon was obviously trapped behind the intraocular implant and excretion was occurring extremely slowly, if at all, therefore requiring its removal. Shammas ${ }^{8}$ and Holtz ${ }^{9}$ have also described similar patients with postoperative myopia, shallow anterior chambers and distended posterior capsular bag due to trapped Healon. 
They chose to release the trapped Healon by creating a hole in the anterior capsule with Nd:YAG laser. This resolved the capsular bag distension, deepened the anterior chamber and corrected the myopic shift. Due to a large capsulorhexis this was not possible in our case as the pupil margin obscured the edge of the capsule even in the dilated state.

We report this case to emphasise the importance of careful and thorough removal of Healon from behind the posterior chamber lens intraoperatively and also to highlight that an unexpected myopic refraction postoperatively may be due to Healon trapped within the capsular bag behind the implant.

\section{References}

1. Goa KL, Benfield P. Hyaluronic acid: a review of its pharmacology and use as a surgical aid in ophthalmology, and its therapeutic potential in joint disease and wound healing. Drugs 1994;47:3536-66.

2. Arshinoff S. The physical properties of ophthalmic viscoelastics in cataract surgery. Proceedings of the National Ophthalmic Speakers Program (NOSP), Montreal. Medicopea International, 1992:7-12.

3. Bothner $\mathrm{H}$, Wik O. Rheology of intraocular solutions. In: Rosen ES, editor. Viscoelastic materials: basic science and clinical applications. Vision and visual health care. Pergamon Press, 1986:53-70.
4. Eisner G. Use of viscoelastic tools in ophthalmic surgery. In: Eisner G, editor. Ophthalmic viscosurgery. Medicopea International, 1986:21-37.

5. Laurant UBG, Fraser JRE. Disappearance of concentrated hyaluron from the anterior chamber in monkey eyes. Exp Eye Res 1990;51:65-9.

6. Miyauchi S, Iwata S. Evaluations on the usefulness of viscous agents in anterior surgery. J Ocular Pharmacol 1989;5:221-32.

7. Laurant UBG, Fraser JRE. Turnover of hyaluronate in the aqueous humor and vitreous body of the rabbit. Exp Eye Res 1983;36:493-504.

8. Shammas HJ. Relaxing the fibrosis capsulorhexis rim to correct induced hyperopia after phacoemulsification. J Cataract Refract Surg 1995;21:228-9.

9. Holtz SJ. Postoperative capsular bag distension. J Cataract Refract Surg 1992;18:310-7.

Anne C. Reck

Professorial Unit

Moorfields Eye Hospital

City Road

London EC 1V 2PD, UK

T. Pathmanathan

Professorial Unit

The Toronto Hospital

Toronto, Canada

R.E. Butler

Eye Department

Queen Alexandra Hospital

Portsmouth, UK 